\title{
Modified three-step procedure to treat buried penis in children without previous surgery: experience in 150 cases
}

\author{
Hanzhong $\mathrm{HE}^{1}$, Pengfei GAO ${ }^{2}$, Sunjie $\mathrm{SUN}^{3}$, Gaoyan $\mathrm{DENG}^{1}$ \\ ${ }^{1}$ Department of pediatric surgery, Guangzhou Women and Children's Medical Center, Guangzhou, Guangdong Province, China. \\ ${ }^{2}$ Department of pediatric surgery, The first affiliated hospital of Sun Yat-sen University, Guangzhou, Guangdong Province, China. \\ Email: surgery4@163,com. ${ }^{3}$ Department of urologic surgery, Shenzhen children hospital, Shenzhen, Guangdong Province, China. \\ Email:sjjym@163.com. \\ Corresponding author: Gaoyan DENG, Department of pediatric surgery, Guangzhou Women and Children's Medical \\ Center,Guangzhou, Guangdong Province, China.Email:denggaoyanemail@163.com. https://orcid.org/0000-0002-8566-998X.
}

Article History Received 5 September 2021; Accepted 25 October 2021; Published 31 December 2021

Cite this Article Hanzhong HE, Pengfei GAO, Sunjie SUN, Gaoyan DENG. Modified three-step procedure to treat buried penis in children without previous surgery: experience in 150 cases [J].Medical Research, 2021.3(4):25-30, http://doi.org/10.6913/mr.0304. $\underline{04}$

Copyright @ 2021 Creative Publishing Co., Limited. All rights reserved. Email:mrhk@mrhk.cc

\section{ABSTRACT}

[Background] The buried penis has an abnormally smaller and shorter appearance. We performed a modified three-step procedure to correct the buried penis with satisfactory cosmetic results.

[Methods] From May 2014 to December 2020, 150 boys, ranging in age from 2 to 7 years old (median age: 3.3 years), underwent this three-step procedure. The chief complaint was a smaller and shorter appearance of the penis. The surgical procedure consisted of three steps: complete degloving through a diamond-shaped penoscrotal incision, circumcision to remove the majority of the inner plate, and anchoring of the penopubic skin to the base of albuginea penis at the 4 and 8 o'clock positions with unabsorbable sutures.

[Results] The mean operative time was 50 minutes (range from 40 to 60 minutes). The mean follow-up time was 2.8 years (range from 10 months to 6 years). There were no complications or recurrences. Good cosmetic results were achieved in all boys.

[Conclusions] Our modified three-step procedure had good cosmetic results without complications. We recommend this effective surgical procedure for boys with buried penis who have no history of previous surgery.

KEYWORDS buried penis; Children; three-step procedure

\section{Introduction}

The buried penis has an abnormally smaller and shorter appearance. Several terms have been used to describe this abnormality in the literature, such as concealed, buried or hidden penis. The etiology is diverse, including sinking of the penis under excessive supra-pubic fat, tethering and shortening of the penis by abnormal fibrous bands, poor penile skin fixation at the penile base, and deficient outer penile skin ${ }^{[1,2]}$. Early surgical treatment has been recommended because of the negative social and psychological factors of a smaller and shorter 
appearance during childhood ${ }^{[3]}$. Many surgical procedures have been described to correct the buried penis. We describe a modified three-step procedure, which includes complete degloving through a diamond-shaped penoscrotal incision, circumcision to remove the majority of the inner plate, and anchoring of the penopubic skin to the base of the albuginea penis at the 4 and 8 o'clock positions.

\section{Methods}

\section{Patients}

Since 2014, we have used a newly designed three-step procedure to correct the buried penis. We defined the buried penis as a penis with an abnormally smaller and shorter appearance (Fig 1). The penis was partially or almost totally buried in supra-pubic tissue, and a normal-size corpora cavernosa penis could be palpated by pressing the tissue around the penis, usually with phimosis. Real micropenis, iatrogenic trapped penis, and obesity were excluded. None of the patients had previously undergone circumcision or other surgeries. Concomitant genital anomalies (including hypospadias and chordee) were also excluded. From May 2014 to December 2020, 150 boys aged 2 to 7 years old (median age: 3.3 years) underwent this three-step procedure. The chief complaint was an abnormal smaller and shorter appearance of the penis. Phimosis could be seen in 140 patients (93\%); the prepuces were retractable in another 10 patients (7\%). Written informed consent was obtained from the patients or parents of the patients.

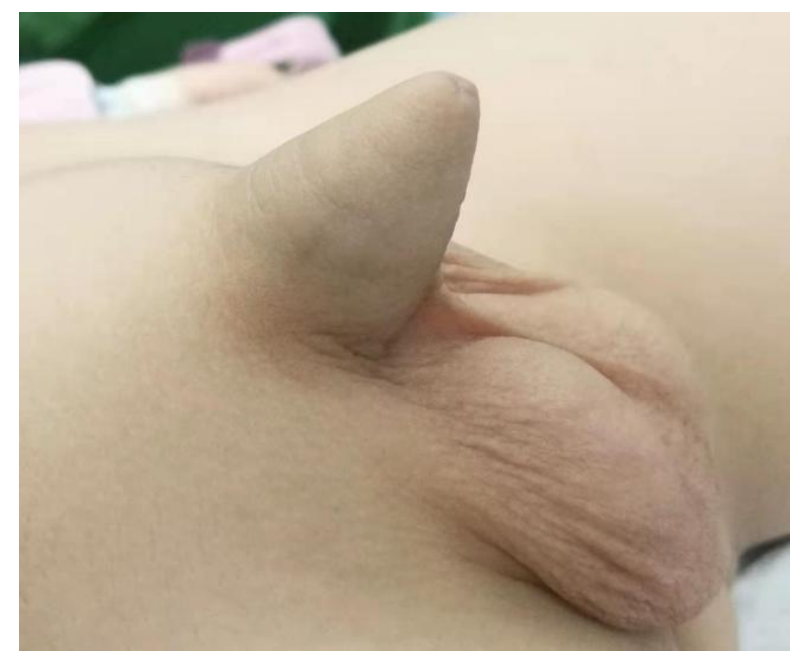

Fig 1. Appearance of buried penis before surgery

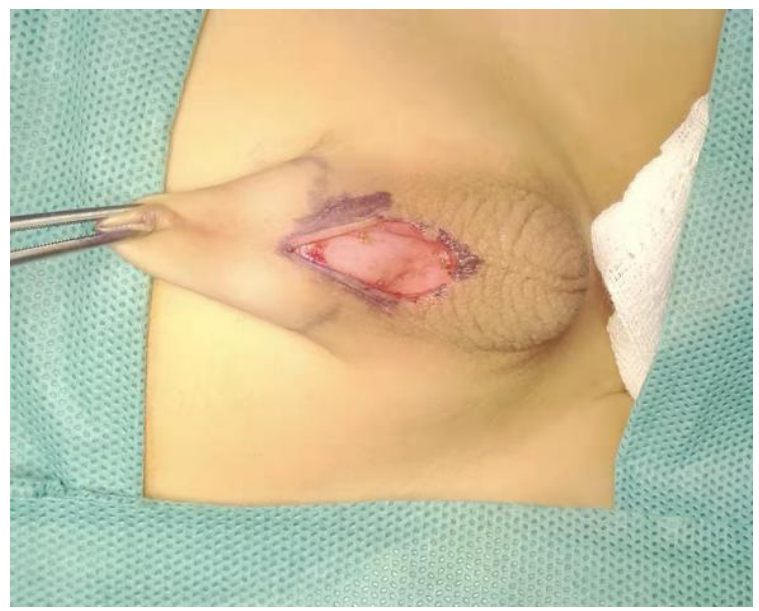

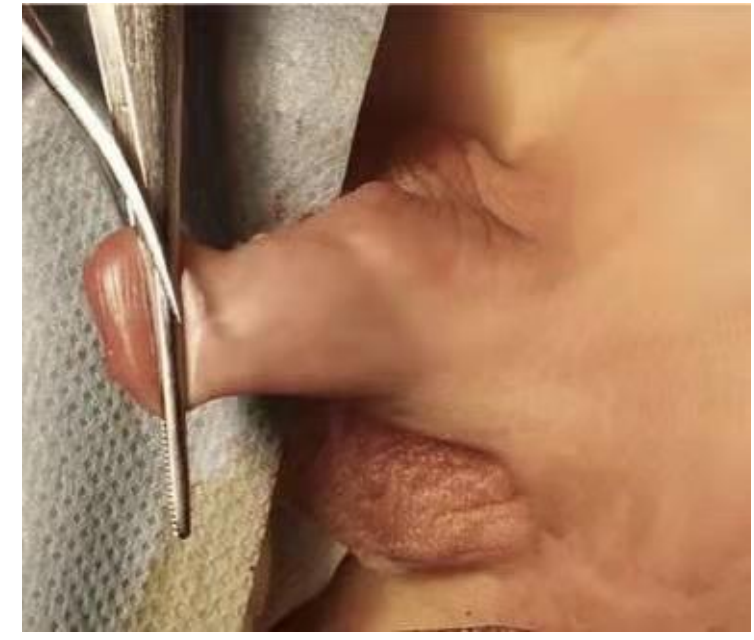

Fig 2. A diamond-shaped incision made in the middle of penoscrotal region

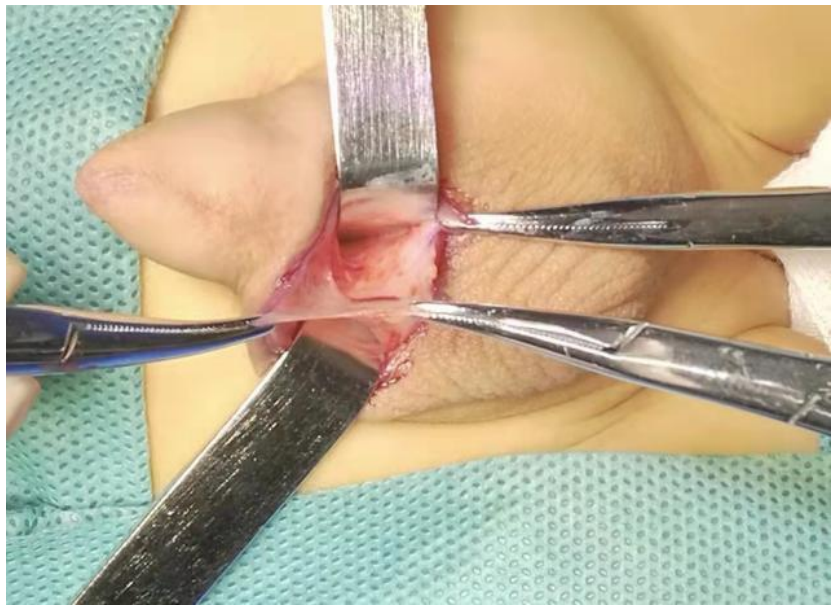

Fig 3. Buck's fascia was identified and cut between the Dartos fascia and the tunica albuginea 


\section{Operative procedure}

\section{Step 1: Degloving}

The procedure started with a diamond-shaped incision (Fig 2) made in the middle of the penoscrotal region. Buck's fascia was identified between the Dartos fascia and the tunica albuginea and was cut by coagulation around the base of the penis (Fig 3). The urethra, dorsal artery and nerve should be avoided during the procedure. Through the incision, blunt dissection was performed to deglove the penis from the penopubic junction to the coronary sulcus. In this procedure, degloving was completely achieved so that the whole penile shaft could be protruded out from the incision.

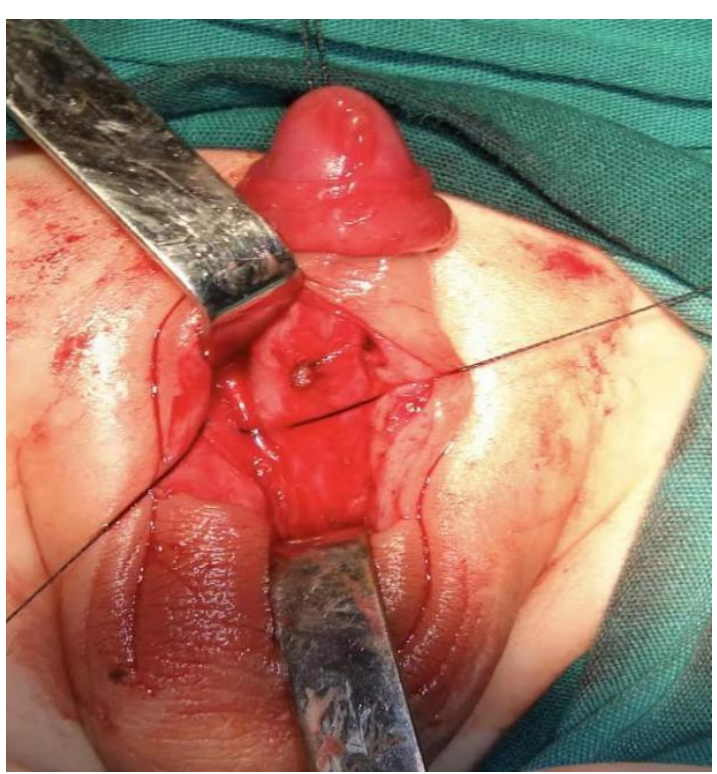

Fig 4. Procedure of fixation

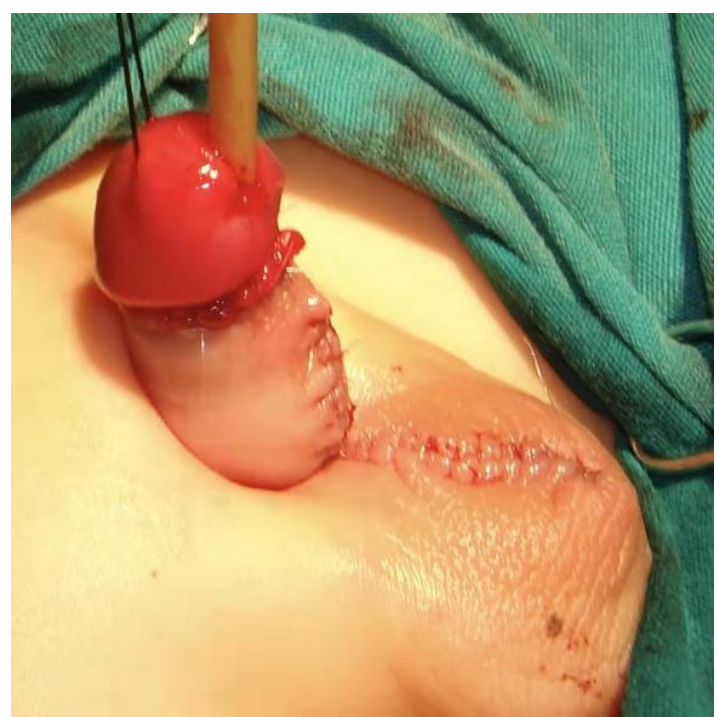

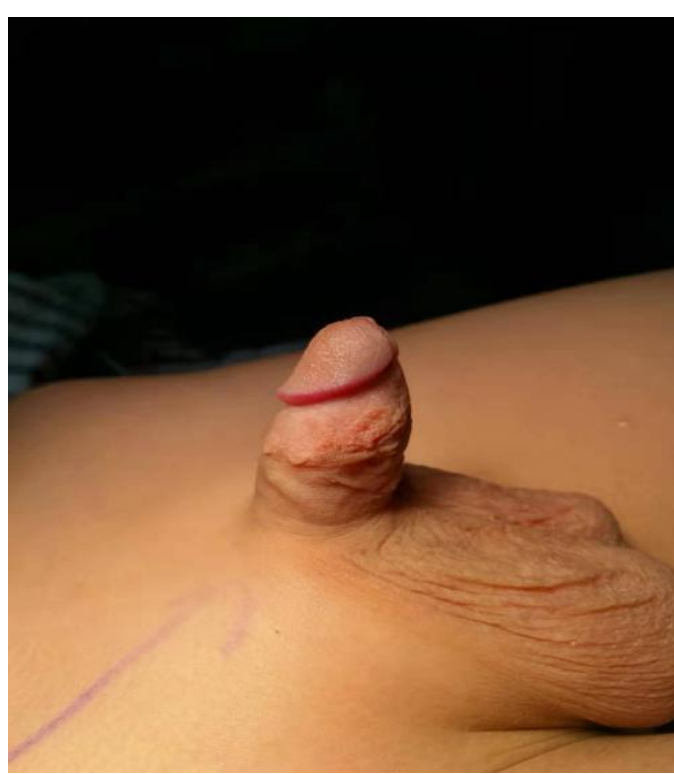

Fig 6.The appearance of penis 2 years later

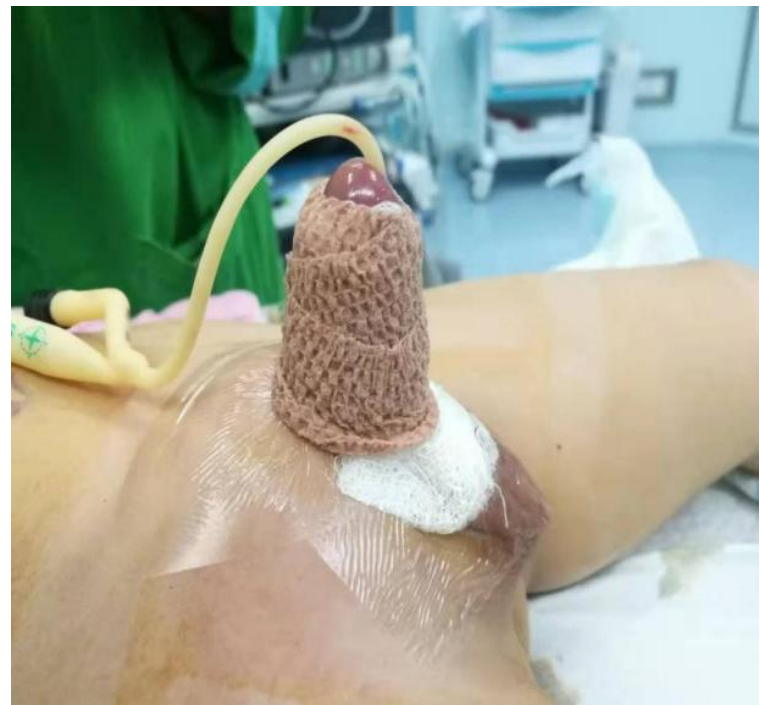

Fig 5.Postoperative lateral view

\section{Step 2: Circumcision}

The narrow tip of the foreskin was cut transversely, the prepuce was retracted backwards, and the glans of the penis was exposed after making two small longitudinal incisions. If the foreskin could be smoothly retracted before surgery, these two small longitudinal incisions were unnecessary. A circumferential incision 
was made beneath the coronary sulcus; then, most of the inner plate of the prepuce was removed, and the outer plate of the prepuce was preserved as much as possible. The circumcision was finished by interrupted sutures using 6-0 Vicryl absorbable suture material.

\section{Step 3: Anchoring}

A Foley urinary catheter was inserted to mark the urethra. Through the penoscrotal incision, two stitches were symmetrically made by unabsorbable sutures between the penopubic skin and the base of the tunica albuginea at the 4 and 8 o'clock positions. The sutures were passed through the subcutaneous tissue and should not be seen from the skin (Fig 4). The dorsal pedicles and corpus spongiosum should not be injured. Finally, 6-0 Vicryl absorbable sutures were used to close the penoscrotal incision longitudinally (Fig 5).

\section{Postoperative care}

The penis was dressed with an inner layer of mesh gauze, and the outer layers were dressed with common cotton gauze. Prophylactic antibiotics were used on the day of the operation and the first day after surgery. The dressing and the Foley catheter were removed three days later, and the patients could be discharged.

\section{Results}

The mean operative time was 50 minutes (range 40-60 minutes), and the mean blood loss was $5 \mathrm{ml}$. With a median follow-up of 2.8 years (range 10 months to 6 years), all boys recovered without complications. All patients had postoperative edema of the inner plate, especially at the site of the frenulum. The more of the inner plate of the prepuce that was reserved, the more serious the edema was. The edema was usually mild and disappeared within 1 month. Longer postoperative edema was observed in only 3 cases (2\%) and resolved within 4 months. There were no other complications or recurrences. Good cosmetic results were achieved in all boys. The appearance changed from cone-shaped to cylindrical, and the penopubic and penoscrotal angles changed from obtuse angles to right or acute angles (Fig 6).

\section{Discussion}

Some surgical procedures have been developed to correct the buried penis, and most surgeons agree a simple circumcision is contraindicated. It is very important to identify such abnormalities from simple phimosis before surgery. Inadvertent removal of excess skin from the penile shaft may cause iatrogenic trapped penis, and reoperations will be very difficult ${ }^{[1,4,5]}$. Surgical techniques for correcting the buried penis include removal of excessive supra-pubic fat, degloving the penile skin, anchoring the supra-pubic skin, and various skin-covering methods ${ }^{[6,7]}$.

Abnormal fibrous attachment is one of the etiologies and can be solved by complete degloving. Radhakrishnan ${ }^{[5]}$ and Borsellino ${ }^{[6]}$ underlined an additional ventral incision in the penile skin to achieve complete degloving. In our experience, it can be easy and effective to relieve anomalous fibrous attachments for patients without previous surgery by cutting Buck's fascia around the base of the penis through a ventral incision. The advantage of complete degloving is that the whole penile shaft could be protruded out from the incision. Degloving may destroy the vascular and lymphatic connections of the prepuce and may cause temporary postoperative penile edema. The diamond-shaped incision made in the penoscrotal region could explicitly improve the penoscrotal angle. 
Adequate skin coverage can be one of the most difficult steps in reconstruction and has a clear impact on the ultimate cosmetic outcome. Circumcision is needed during the surgical management of the buried penis, and the excess inner mucosa should be excised ${ }^{[8]}$. Edema and swelling on the preputial flaps are common ${ }^{[9,10]}$, and we do not consider the inner plate of the prepuce as a good material for penile reconstruction. If too much of the inner plate was reserved, a cosmetic problem would exist for quite a long time ${ }^{[11,12,13]}$. In our operative technique, we prefer to remove most of the inner plate to reduce preputial edema. However, for patients with multiple previous surgeries, skin coverage would be a challenge because of excess scarring. The inner plate should not be cut too much and should be used to cover the wound.

Eun-hong Jung et al. ${ }^{[14]}$ reported that insufficient exposure of the penile shaft and poor fixation of the penile skin (instead of abnormal fibrous bands) could cause the abnormal appearance of the buried penis. Anchoring the prepubic skin to the penile shaft should limit the normal gliding movement of the penile shaft in its covering skin structure. We agree with their statement. No supra-public incision was made during our subcutaneous sutures. The penopubic angle was established, and the skin and the shaft were fixed very well by two unabsorbable sutures between the penopubic skin and the tunica albuginea. The penis had a more distinct border, resulting in good cosmetic outcomes. In some articles, more stitches (such as four stitches) have been used for anchoring ${ }^{[15]}$. However, we think that two stitches are sufficient. It is reasonable to believe that fewer stitches will definitely reduce the chances of bleeding from the corpus cavernosum, injury to the urethra or corpus spongiosum, and injury to the dorsal vascular nerve bundles. Some surgeons worry about the sutures loosening after a long time and that the penis would become buried again. However, this phenomenon did not occur in our patients during follow-up. Perhaps a longer follow-up is necessary. Our procedure is recommended for patients who had no history of previous surgeries and no scars; otherwise, other techniques should be performed.

\section{Conclusion}

We modified the three steps of the operation, including degloving, circumcision and anchoring. Good cosmetic results were achieved with few complications. We recommend this effective surgical procedure for patients with buried penis who have no history of previous surgeries.

\section{References}

1.Gillett MD, Rathbun SR, Husmann DA et al. Split-thickness skin graft for the management of concealed penis. J Urol 2005; 173: 579-582.

2.Perger L, Hanley RS, Feins NR. Penoplasty for buried penis in infants and children: report of 100 cases. Pediatr Surg Int 2009; 25: 175-180.

3.Tai-Wai Chin. Buried penis. Formosan Journal of Surgery 2016; 49: 133-135.

4.Li Z, Wei D, Guizhen H, Miao Y et al. Pedicled skin flap of foreskin for phalloplasty in the management of completely concealed penis. J Pediatr Surg 2012; 47: 2289-2293.

5.Sivakumar B, Brown AA, Kangesu L. Circumcision in 'buried penis'-a cautionary tale. Ann R Coll Surg Engl 2004; 86: 35-37.

6.Radhakrishnan J, Razzaq A, Manickam K. Concealed penis. Pediatr Surg Int 2002; 18: 668-672.

7.Borsellino A, Spagnoli A, Vallasciani S, et al. Surgical approach to concealed penis: technical refinements and outcome. Urology 2007; 69: 1195-1198.

8.AT Hadidi.Buried penis: classification surgical approach. Journal of Pediatric Surgery 2014; 49 :374-379. 
9.Chu CC, Chen YH, Diau GY, et al. Preputial flaps to correct buried penis.Pediatr Surg Int 2007; 23: 11191121.

10. Alexander A, Lorenzo AJ, Salle JL, et al. The Ventral V-plasty: a simple procedure for the reconstruction of a congenital megaprepuce. J Pediatr Surg 2010; 45: 1741-1147.

11.Senaylı A, Senayl1 Y. A novel operative technique for concealed penis secondary to penoscrotal web: a case report. Ther Adv Urol 2010; 2: 215-218.

12. Yang T, Zhang L, Su C, et al. Modified penoplasty for concealed penis in children. Urology 2013; 82(3):697-700

13.Chin TW, Tsai HL, Liu CS. Modified prepuce unfurling for buried penis: a report of 12 years of experience. Asian J Surg. 2015; 38(2):74-78.

14.Jung EH, Son JH, Jang SH et al. Simple anchoring of the penopubic skin tothe prepubic deep fascia in surgical correction of buried penis. Korean J Urol 2011; 52: 787-791.

15.Cheng G, Liu B, Guan Z, et al. A modified surgical procedure for concealed penis. Can Urol Assoc J. 2015; 9 :E723-726. 